\title{
Not purely academic! Supporting teachers and researchers in psychology
}

\author{
Fiona Lyddy ${ }^{\mathrm{a}}$ and Nicola Porter ${ }^{\mathrm{b}}$ \\ ${ }^{a}$ Department of Psychology, National University of Ireland, Maynooth, Ireland; ${ }^{b}$ Dun Laoghaire \\ Institute of Art, Design \& Technology, Ireland
}

(Received 2 May 2013; accepted 30 October 2013)

\begin{abstract}
The Division of Teachers and Researchers in Psychology (DTRiP) was established in 2007 in order to represent the views of psychology teachers and researchers within the Psychological Society of Ireland (PSI) and to continue the work of the Teachers of Psychology Interest Group (TPG), which was active within the PSI in the 1980s. The activities of the Division reflect the objectives set out in the Division rules: to promote best practice in teaching and research in psychology; to provide a forum for the sharing of psychological knowledge and expertise; to promote and maintain high ethical and professional standards; to promote and encourage scientific research as it applies to teaching and learning and to promote the use of scientific methods in research; and to liaise with relevant bodies in the promotion of the Division goals. In the current paper, we outline some of the ways in which the Division has contributed to the Society's functions since its foundation, and we consider issues of relevance to the future development of the Division.
\end{abstract}

Keywords: teaching of psychology; psychology

\section{Foundation of the Division}

At the General Meeting held at the Psychological Society of Ireland (PSI) Annual Conference in November 2007 in Killarney, members unanimously supported the foundation of a new division within the PSI, the Division of Teachers and Researchers in Psychology (DTRiP), following a motion that was proposed by Fiona Lyddy (National University of Ireland Maynooth) and seconded by Christopher Alan Lewis (then at the University of Ulster, now at Glyndŵr University, Wales). The proposal to the meeting followed several years' discussions among teachers and researchers, at the PSI conference and other events, concerning the need for formal representation within the PSI structures for members who were teachers, researchers and academics. Around that time, a number of academic members, including Lyddy and Lewis, were serving on the PSI Council, and the value of, and the need for, a continued contribution to PSI from this section of the membership was noted. Since the PSI was established in 1970, the contribution of academic members has been apparent in a variety of roles. Their influence is reflected in the Society's publications The Irish Journal of Psychology (published since 1971) and The Irish Psychologist (published since 1974), and the Society's contributions to international publications. It is also evident in contributions to workshops and seminars, in motions to general meetings and in memberships of Boards, Committees, Groups and

*Corresponding author. Email: fiona.lyddy@nuim.ie 
the PSI Council itself. The Division was established with the intention of recording that contribution within a formal PSI structure and ensuring that this contribution continued to be recognised in the future. It was in this spirit that the Division was launched, and the demand for the formal representation of teachers and researchers is reflected in the unanimous support of members at the general meeting, as well as the support of the proposing members (listed in Appendix 1), many of whom had made important individual contributions to the promotion of teaching and research within the Society over many years.

The Division held its founding meeting on 26 April 2008 at Trinity College Dublin. The meeting was chaired by Suzanne Guerin on behalf of the PSI President, Mitchel Fleming. At that meeting, Fiona Lyddy was elected as founding Chair, with Christopher Alan Lewis elected as Secretary and Conor McGuckin as Treasurer. Sharon Mary Cruise, Deirdre Desmond and Suzanne Guerin were also elected as committee members, with six further members co-opted to the committee: Maria Dempsey, Suzanne Egan, David Hevey, Brian Hughes, Nicola Porter and Ronan Yore. The committee included teacher and researcher representatives from the institutions providing psychology training and education across the country, including north of the border. The newly formed committee admitted 35 founding members to the Division. Nicola Porter (Dun Laoghaire Institute of Art, Design \& Technology) became Chair in November 2009. The current committee (as of 2010) is listed in Appendix 2.

\section{Aims and membership}

The key aims of the Division, as set out in its rules, include the following: to promote best practice in teaching and research in psychology; to provide a forum for the sharing of psychological knowledge and expertise; to promote and maintain high ethical and professional standards among teachers and researchers in psychology; to promote and encourage scientific research as it applies to teaching and learning within psychology and to promote the use of scientific methods in psychological research; to liaise with relevant bodies in the promotion of the goals of the Division and its members; and to represent the views of psychology teachers and researchers within the PSI.

By 2010, DTRiP had 40 members. Full membership of the Division is open to graduate members of the Society who: (1) hold a doctoral qualification recognised by the Society and have at least one year's full-time, or equivalent, relevant experience as a teacher and/or researcher in psychology; or (2) hold a postgraduate qualification in psychology recognised by the Society and have at least two years' full-time, or equivalent, relevant experience as a teacher and/or researcher in psychology. Affiliate membership of the Division is open to graduate members or other subscribers to the Society who are undertaking postgraduate training or are working as a teacher and/or researcher in psychology, and is granted for a period of four years. Since 2008, the Division has organised a number of events to promote its aims including an invited lecture at the Division's annual general meeting, a symposium at the PSI Annual Conference, and workshops and training events designed for postgraduate students in particular.

\section{Teachers and researchers pre-DTRiP}

Interest in a group for teachers and researchers predates the foundation of the Division by many years, with one group within the PSI, the Teachers of Psychology Interest Group 
(TPG), particularly active in the early to mid-1980s. A meeting was convened at the 1983 Annual Conference in Athlone to gauge interest in setting up a group specialising in the teaching of psychology. Approximately 40 members of the PSI attended the meeting, and Stuart Lewis (Chairperson), John Groeger (Hon. Secretary/Treasurer), Noirin Hayes, Liz McWhirter and Mike Nolan were elected to the Steering Committee for the group. According to a short report in the PSI Developments section of The Irish Psychologist (February 1984), the TPG's aims were:

(1) To advance skills in the teaching of psychology to diverse groups;

(2) To promote discussion of and promulgate information about methods of psychological education, including such issues as assessment of teaching practice, methods of assessing student learning, structure of courses, teaching and learning resources;

(3) To liaise with other relevant groups and to represent the views of its membership.

The TPG and its aims were formally approved at the January 1984 meeting of the PSI Council. The inaugural meeting of the group was held on Friday, 18 May 1984, in the Department of Psychology, Trinity College Dublin. The meeting was chaired by Des O'Mahony of the Department of Justice, Dublin and included a number of presentations on the theme of 'Teaching and Evaluating Teaching: Life Span Development'. In November of that year, Ronny Swain (University College Cork) presented a workshop on behalf of the group titled 'Versatility in Teaching' at the PSI Annual Conference in Westport, with 20 participants invited to discuss their versatility as teachers having reflected on their own experience of learning.

The group is mentioned in the October 1985 issue of The Irish Psychologist, listed among the PSI Committees, Working Parties, Boards and Groups for 1985-1986. The group disappeared from the PSI records after that date. However, there is no doubt that the groups of individuals specifically interested in the teaching of psychology and in psychological research were still active, and a number of events and workshops, at PSI and elsewhere, over subsequent years suggest this. For example, a symposium on 'European Perspectives in Teaching Psychology' was presented at the Annual Conference of The British Psychological Society (BPS), Scarborough, 9-12 April 1992, with Ireland, Norway, Portugal, Spain and the UK represented (see Swain, Taylor, \& O'Connor, 1992).

Unlike DTRiP, the TPG did not limit its membership to those in teaching or researcher posts; any member psychologist with an interest in the area was welcome to join. One of the disadvantages of the formal division structure is the rather strict criteria for membership; however, links to Society registered membership mean that strict criteria must, and should, be maintained. However, affiliate membership might be expanded somewhat in the future. In establishing the Division, it was hoped that a more permanent structure within the PSI would facilitate the recording of contributions, provide an organised means of supporting teachers and researchers, and provide a formal structure that PSI could call on for input to national and international consultations.

The changing context of psychology education in Ireland and issues around regulation of the profession provided the impetus for the foundation of the Division. In what follows, three influences are considered: the growth of psychology at third level; changes that may come with statutory regulation of the profession; and the proposed introduction of psychology at second level. 


\section{Growth of psychology at third level}

Twenty years ago, undergraduate psychology degrees were offered at four universities (Trinity College Dublin, University College Cork, University College Dublin and University College Galway), with an estimated 200 students graduating annually (Swain et al., 1992), and 123 postgraduate students were registered for higher degrees in psychology (Brady \& McLoone, 1992). The first undergraduate qualification in psychology to be offered in the Republic of Ireland was a two-year diploma introduced by University College Dublin in 1958 (Brady \& McLoone, 1992; Brock, 2012), with a degree programme following in 1967. Trinity College Dublin and University College Cork introduced psychology degree programmes in 1964, and University College Galway launched its programme in 1971 (Brock, 2012). In the past decade, there has been a substantial increase in the number of psychology courses on offer and the number of graduates completing programmes nationally. All of the country's universities now offer undergraduate psychology programmes, with the National University of Ireland Maynooth introducing a psychology programme in 2000, and the University of Limerick launching its first psychology degree in 2008. Dublin City University has recently introduced a psychology degree. PSI-accredited undergraduate programmes in psychology are also offered by Dun Laoghaire Institute of Art, Design and Technology, Mary Immaculate College, Limerick, Waterford Institute of Technology, and Dublin Business School. In addition, a number of Higher Diploma conversion programmes are offered, which are also accredited by PSI, and provide graduates of disciplines other than psychology with an opportunity to attain the basis for graduate membership of PSI. The growth in the number of psychology places, and graduates, mirrors developments in other European countries, including the UK, where over $80 \%$ of psychology graduates choose employment routes (initially at least) other than professional training in psychology (Trapp, 2008).

\section{Accreditation of psychology degrees and statutory regulation}

PSI, through its course accreditation, has influenced psychology education throughout the country (Swan, 2002), and has shaped the way in which the subject is taught. At postgraduate level, PSI accredits courses on clinical, counselling, educational, forensic, health and work and organisational psychology. Accreditation of undergraduate degrees aims to ensure that courses prepare students appropriately for entry into any of the specialist areas within psychology, and ensures a certain level of consistency in undergraduate provision across the various institutions. The undergraduate accreditation guidelines of PSI are similar to those of the BPS, with a focus on research throughout the degree years and coverage of core areas: biological bases of behaviour; developmental and lifespan psychology; social psychology; personality and individual differences; cognitive psychology; research design, quantitative and qualitative methods (PSI Accreditation of undergraduate courses guidelines, 2004).

Traditionally, psychology degrees in Ireland were accredited by both PSI and the BPS. By 2003, the BPS had begun restricting its accreditation to courses within the UK. The withdrawal of the BPS was potentially problematic for graduates of Irish courses, whose programmes would no longer be recognised by UK-based course providers at the postgraduate level. This situation was alleviated by the hard work of several academics, including members of DTRiP, who worked to ensure that accredited psychology programmes in Ireland would continue to be recognised in the UK. Graduates of PSI-accredited courses who are eligible to apply for graduate membership can apply for 
the BPS Graduate Basis for Chartership (GPC) as overseas applicants. A memorandum of cooperation was signed on behalf of the society by then president of PSI, and DTRiP committee member, Suzanne Guerin, in October 2006. The memorandum records a formal agreement, between the two societies, of recognition of each other's undergraduate accreditation procedures. This was an important step in maintaining the mobility for psychology graduates in the UK and Ireland. While some difficulties have arisen, from time to time, as regards recognition (for example, anecdotally, the expectation that Irish courses are BPS accredited remained in some UK institutions), DTRiP has been able to monitor developments and respond, through the PSI Council, to concerns.

While statutory regulation and registration of psychologists in Ireland is imminent for our colleagues in the other divisions, it remains to be seen how registration will affect psychology teachers and researchers. DTRiP members have been involved in a number of consultations concerning statutory registration. At the time of writing, the registration board for psychologists has not yet been established, and the impact on accreditation of psychology programmes is not yet clear.

\section{Psychology at pre-tertiary level}

Psychology is currently not available as a pre-tertiary subject of study in Ireland. This may change, however, as the National Council for Curriculum and Assessment (NCCA, 2009) has developed a draft short course in psychology, aimed at Leaving Certificate students. The Division has a key role to play in monitoring such developments and giving feedback to the appropriate bodies, in support of the aim to promote best practice in teaching and research in psychology. A number of DTRiP members have provided input to the consultation process, and the Division's composition, in terms of institutional representation and range of subject-specific expertise, has been very useful in this regard.

The draft short course in psychology emerged from the NCCA's review of Senior Cycle curriculum and assessment. Senior Cycle (upper secondary) can be of two or three years duration, depending on whether or not a student takes a transition year, and it culminates in a public examination, normally at age 17 or 18 years, the Leaving Certificate (Department of Education and Science, 2004). Short courses, such as the proposed psychology course, are a new concept in Leaving Certificate options. They are proposed as 90-hour courses of study that would be completed and assessed in one year. Students could take one or more short courses in their penultimate and/or final year and each short course would contribute half the Leaving Certificate examination points of a traditional, two-year subject. (Points are awarded for results across a maximum of six subjects in the Leaving Certificate examination, and determine the entry to third-level courses.)

The Chair of DTRiP at the time of writing, Nicola Porter, was involved in the development of the draft short course in psychology and members of the Committee, and indeed the Division, have also provided feedback during the NCCA consultation. Several members attended a public consultation meeting on the short course in October 2011. The course aims to provide students with a general introduction to psychology; its content includes some influential theories and main themes, along with a variety of methods. It is designed to be useful to students in a number of different ways: encouraging them to be critically aware of how psychology is presented in the media; helping them to apply what they have learned to their everyday lives; and introducing them to what it would be like to do further study in psychology and perhaps even work in the area. The course also provides students with the opportunity to develop five key skills: information processing, 
critical and creative thinking, communicating, working with others, and being personally effective. The NCCA's key skills framework is outlined on their website: www.ncca.ie. A period of consultation on the draft course has recently concluded and it will shortly be reviewed in light of the suggestions made by psychology teachers and researchers, and others.

What are the implications of the short course, should it come into being, for the teaching of psychology at third level? Psychology has been offered at pre-tertiary level for some years in the UK, and there is much to learn from the UK experience. In the UK, A level Psychology has grown rapidly. In 2010, psychology was the fourth most popular A level in the UK (DTRP Newsletter, 2011, May) and a majority of students who take psychology at university have already taken the subject at school (Trapp, 2008). However, while the majority of psychology students at university in the UK have studied psychology before, 'the articulation between school psychology and first year psychology is problematic and, in general, not highly valued at first year undergraduate level' (Trapp, 2008, para. 2).

One reason for this is the negligible effect of A level psychology experience on performance at degree level. For example, Banister (2003) found that, with the exception of an initial advantage in statistics, having A level psychology did not affect undergraduate students' grades. Similarly, Betts, Elder, Hartley, and Blurton (2008) found that having A level psychology, even with a high grade attained, did not affect performance at degree level. Jarvis (2011) notes that the opportunity to write essays in A level Psychology has decreased substantially since 2000 while report-writing has not been required since 2008, suggesting that key skills that might transfer to the degree level are not being developed at school. There is sometimes a sense that "the "gold standard" of A level (is) heavy on volume and light on skills development' (Jarvis, 2007, p. 614) and that positive experiences of A level psychology are due to the commitment and skills that an individual teacher brings to the course.

However, teachers of A level Psychology vary considerably in terms of their own experience of the subject (a qualification in psychology is not required to teach the subject), and this is reflected in some teachers' attitudes towards the discipline, particularly as regards attitudes to psychology as a science. The Qualifications and Curriculum Authority (QCA) and the Office for Standards in Education (Ofsted) classify psychology as a science, and an important aspect of pre-tertiary education is to accurately reflect the scientific nature of the discipline. Yet, many second-level teachers of psychology are not convinced of its scientific basis. Rowley and Dalgarno (2010) surveyed 109 A level psychology teachers regarding their attitude to psychology as a science, among other things. They found that while psychology teachers generally agreed that psychology is a science, they did not believe the subject was as scientific as 'harder sciences' like physics and chemistry. However, the rigour of the A level curriculum would not seem to be in question, and an intersubject comparability study carried out by the QCA found that standards were equivalent in psychology and biology (QCA, 2008). Yet, psychology continues to be seen as a 'softer option' for A level students, and there has even been some concern, particularly in the media, that it reduces the likelihood of being admitted to certain universities (Jarvis, 2011).

Most universities in the UK do not require students to have a pre-degree qualification in psychology, and psychology teaching at third level has largely continued as if the subject were not offered at school. As Jarvis (2007) comments, 'conventional wisdom has long held that taught psychology at this level is of no concern to the psychology world at large' (p. 614). However, he also notes that this stance may have begun to change 
recently, given the huge increase in students taking psychology at school; the numbers taking A levels in psychology have increased from 30,000 in 2000 to almost 55,000 in 2010 (Joint Council for General Qualifications). Toal (2007) notes a number of difficulties facing psychology at A level, and highlights the need for professional bodies for the discipline to influence the curriculum and teaching practices. In a special issue of The Psychologist on pre-degree psychology, Trapp (2007) discusses particular issues concerning subject coverage, teacher training, and linear progression, and notes that 'for too long, these difficulties have resulted in what amounts to an uneasy stand-off between pre-tertiary and higher education programmes of psychology' (p. 607).

In the UK, the Association for the Teaching of Psychology was established over 25 years ago to support psychology teachers at second level, and in particular addresses issues faced by teachers who are the only psychology teachers at their school. The Division may need to consider relationships with such groups in the future should second-level psychology become a reality in Ireland. As a Division, our aims include the desire to contribute to continuing professional development for psychology teachers, to raise the profile of the role of the teacher in psychology, to promote high ethical and professional standards among teachers, to represent the views of teachers within PSI, and to contribute to the development of relevant policy. But to what extent will this apply to second-level psychology teachers, who may or may not have a qualification in psychology?

\section{Comparison to other groups: an opportunity for reflection}

As a relatively new Division within the PSI, DTRiP has been keen to learn from other groups, and there are a number of international groups that are concerned with the teaching of psychology and the experience of, and support for, teachers and researchers. The BPS's Division of Academics, Researchers and Teachers in Psychology (DARTP), which was formerly the Division for Teachers and Researchers in Psychology (DTRP), was established in 1997 to represent members following careers in teaching and/or research. DARTP provides its members with many useful support services, including a regular newsletter and the peer-reviewed Psychology Teaching Review. DARTP host their inaugural conference in 19 April 2012 in London. The theme for the first conference will be 'student engagement in a changing economic climate'. They currently have 619 members (DTRP Newsletter, Autumn 2011).

DARTP has much in common with DTRiP, not least in terms of its vision and aims. It does have a different membership structure, however. Both DARTP and DTRiP have a Full Membership category and an Affiliate Membership category, but it is arguably more difficult to become a full member of DARTP than a full member of DTRiP. There is a good reason for this; in BPS, a teacher of psychology can become a chartered member on the basis of their teaching experience. DARTP also has a Corresponding Membership category open to all other members of BPS (e.g., Student Subscribers) who are not eligible for either of the other two membership categories.

European Psychology Learning and Teaching (EUROPLAT; http://www.europlat.org/) is a relatively new development. Established in 2009, it is an academic network that supports psychology learning and teaching across 31 countries. Most of its members are academic departments and schools. The network engages in research projects (for example, see Reddy, Hammond, Lewandowska, Trapp, \& Marques, 2011) and organises networking events including the EUROPLAT conference. DTRiP is an associate member of EUROPLAT. Associate members participate on a self-funding basis but this relationship 
is highly beneficial to a relatively small group like DTRiP, providing a stronger connection with the wider psychological community and access to project deliverables, including research papers, newsletters and innovation reports. In addition, there are frequent opportunities for involvement in various discussions, events and annual conferences.

The Society for the Teaching of Psychology (STP; http://teachpsych.org/) is the American Psychological Association's (APA) Division 2. They have an extensive range of resources for psychology teachers at all levels, many available on their website, including the Office of Teaching Resources in Psychology (OTRP) which offers a wide variety of peer-reviewed teaching materials. APA membership is not a requirement for STP membership.

In addition, the UK's Higher Education Academy (HEA) subject centre for psychology, based at the University of York, developed some very useful resources for teachers of psychology. In the years that the centre operated (2004-2011), it produced a range of supports and resources for teachers, some of which will be retained under the restructured system, which has positioned psychology within STEM (science, technology, engineering and mathematics; see http://www.pnarchive.org/ for the archived resources).

A comparison of DTRiP with groups like DARTP and STP raises a number of issues to do with membership. In our overview of the TPG, we have already referred to the Division's rather strict criteria for membership. DARTP has similar criteria but also allows for subscriber members. One does not need to be a member psychologist to join STP. Of course, both of these organisations operate on a completely different scale to DTRiP. However, as we are to grow our membership we need to consider what we can do to attract more members within the PSI and how we might involve the many teachers and researchers who are not PSI members.

A comparison with other groups could also lead us to ask the question: who exactly do we represent and why? Like our predecessor, the TPG, most other groups solely represent teachers, not researchers. The BPS's DARTP is the exception, although many of that group's activities are teacher-centred: their journal is called Psychology Teaching Review, and the theme of their upcoming inaugural conference is teachingrelated. Since its inception, DTRiP has tried to have at least one member of the Committee who is in a research post, and has attempted to have an equal balance of teaching and research focused events. However, despite these efforts, and the Division's aims, there is no doubt that our focus tends to be more on teaching-related issues (as reflected in the three influences considered in the main text of this paper). Future development of the Division may require increased attention to more research-related issues and/or a reexamination of exactly who we represent, and who we are best placed to represent.

\section{Summary}

In the current paper, we have outlined some of the ways in which the Division has contributed to the Society's functions to date, and we have considered issues of relevance to future development of the Division, including the growth of psychology at third level, developments in Ireland at second level and implications of statutory regulation for accreditation. We have also outlined ways in which we might learn from other groups, as the Division assesses its progress over the few years since its foundation, and looks to grow its membership in the future, in support of PSI's aims to promote a high standard of psychology education in Ireland. 


\title{
Acknowledgements
}

A special note of thanks to Ronny Swain, Mitchel Fleming, Shaun Adams (former PSI Director of Operations) and Una Ní Bhroithe for helping us to compile the information on the Teaching of Psychology Interest Group.

\section{References}

Banister, P. (2003). Impact of post-16 qualifications on the undergraduate curriculum: Views from heads of psychology departments. In C. McGuinness (Ed.), Post-16 qualifications in psychology. Leicester: British Psychological Society.

Betts, L., Elder, T., Hartley, J., \& Blurton, A. (2008). Predicting university performance in psychology: The role of previous performance and discipline-specific knowledge. Educational Studies, 34, 543-556. doi:10.1080/03055690802288528

Brady, T., \& McLoone, J. (1992). Ireland. In V. Staudt Sexton \& J. D. Hogan (Eds.), International psychology: Views from around the world (pp. 229-239). Nebraska: University of Nebraska Press.

Brock, A. C. (2012). Ireland. In D. B. Baker (Ed.), Oxford handbook of the history of psychology (pp. 289-306). New York, NY: Oxford University Press.

Department of Education and Science. (2004). A brief description of the Irish education system. Dublin Ireland. Retrieved from http://www.education.ie/en/Publications/Education-Reports/ABrief-Description-of-the-Irish-Education-System.pdf

DTRP Newsletter. (2011, Autumn). Retrieved from http://trp.bps.org.uk/dtrp/divisionpublications/ newsletter-archives.cfm

DTRP Newsletter. (2011, May/June). Retrieved from http://dtrp.bps.org.uk/dtrp/divisionpublica tions/newsletter-archives.cfm

Jarvis, M. (2007). Who nurtures the nurturer? The Psychologist, 20, 614-616.

Jarvis, M. (2011). Defending the honour of psychology A-level. The Psychologist, 24, 674-675.

National Council for Curriculum and Assessment. (2009). Psychology: Draft short course for consultation. Dublin, Ireland. Retrieved from http://www.ncca.ie/en/Curriculum_and_Assessment/Post-Primary_Education/Senior_Cycle/Consultation/Psychology_syllabus.pdf.

Psychological Society of Ireland. (2004). Accreditation of undergraduate courses guidelines. http:// www.psihq.ie/page/file dwn/9/accreditation-undergrad-guidelines.pdf.

Qualifications and Curriculum Authority. (2008). Inter-subject comparability studies. London: QCA. Retrieved 5 August 2012 from www.ofqual.gov.uk/1551.aspx

Reddy, P., Hammond, J., Lewandowska, A., Trapp, A., \& Marques, J. F. (2011). Innovation in the teaching of psychology in higher education in the EU. Retrieved from http://www.europlat.org/ cmseuroplat/docs/pdf/EUROPLAT\%20INNOVATION\%20REPORT.pdf.

Rowley, M., \& Dalgarno, E. L. (2010). A-level psychology teachers: Who are they and what do they think about psychology as a subject and a discipline?. Psychology Teaching Review, 16, 2.

Swain, R., Taylor, M., \& O'Connor, M. (1992). The teaching of psychology in Ireland. Psychology Teaching Review, 1, 82-84.

Swan, D. (2002, June). Psychology education in Ireland. Paper presented at the International Conference on Psychology Education, ICOPE 2002, Saint Petersburg, Russia.

Toal, J. (2007). Teaching a level psychology. The Psychologist, 20, 612-613.

Trapp, A. (2007). Nurturing the next generation. The Psychologist, 20, 607.

Trapp, A. (2008, July). The changing nature of psychology education in the UK. Paper presented at the Third International Conference on the Teaching of Psychology, Saint Petersburg, Russia.

\section{Appendix 1. Members proposing to PSI Council the establishment of a Division of Teachers and Researchers in Psychology (July 2007; listed in alphabetical order)}

\author{
Barnes-Holmes, Dermot \\ Cruise, Sharon Mary \\ Cullinan, Veronica \\ Desmond, Deirdre \\ Dooley, Barbara \\ Egan, Suzanne
}


Fuller, Ray

Gallagher, Pamela

Greene, Sheila

Guerin, Suzanne

Hevey, David

Ivers, Mary

James, Jack

Leader, Geraldine

Lenihan, Carol

Leslie, Julian

Lewis, Christopher Alan

Lyddy, Fiona

MacLachlan, Mac

McGann, Marek

McGilloway, Sinéad

McGuckin, Conor

Moran, Aidan

O'Hora, Denis

Sarma, Kiran

Smith, Howard

Stewart, Ian

Swain, Ronny

\section{Appendix 2. Committee members (in 2010)}

Nicola Porter (Chair)

David Hevey (Secretary)

Deirdre Desmond (Treasurer)

Maria Dempsey

Suzanne Egan

Suzanne Guerin

Brian Hughes

Olivia Hurley

Fiona Lyddy (Past Chair)

Aileen O'Reilly 